\title{
Artillería y cureñas del baluarte de Santiago, Veracruz. Una aproximación histórica al patrimonio militar de México
}

\author{
The artillery and gun carriages of the baluarte de Santiago, Veracruz: \\ historical approach to the military heritage of Mexico \\ Eder Antonio de Jesús Gallegos Ruiz ${ }^{1}$ \\ Universidad Pablo de Olavide, Sevilla-España
}

\begin{abstract}
RESUMEN
El objetivo de este artículo es realizar un estudio histórico detallado a partir de indicios arqueológicos surgidos en 2018, durante el proceso de restauración del Baluarte de Santiago en la ciudad mexicana de Veracruz. Las señas materiales en el sitio incitan a realizar preguntas desde la metodología histórica respecto a las diversas tipologías de cañones y soportes utilizados en esta defensa costera, no solo desde la descripción sino que pretende ahondar en sus mecanismos de adquisición estatal durante los variados regímenes políticos, desde el periodo virreinal hasta el México decimonónico. El fin último es entender a dichos instrumentos bélicos y sus cureñas como indicadores del proceso de construcción del Estado moderno y poner de relieve la importancia del patrimonio militar.
\end{abstract}

Palabras clave: Patrimonio militar; seguridad marítima; estado; artillería.

\begin{abstract}
The objective of this article is to carry out a detailed historical study based on archaeological evidence that emerged in 2018, during the restoration process of the Baluarte de Santiago in the Mexican city of Veracruz. The material signs on the site incite questions from the historical methodology regarding the various typologies of canyons and supports used in this coastal defense, not only from the description but also aims to delve into their mechanisms of state acquisition during the various political regimes from the viceregal period to nineteenth-century Mexico. The ultimate goal is to understand these war instruments and their gun carriages as indicators of the process of construction of the modern State and to highlight the importance of military heritage.
\end{abstract}

Key words: Military heritage; maritime security; state; artillery.

\section{PRESENTACIÓN}

Abordar las tipologías de las piezas de artillería y de sus cureñas en una fortificación requiere entender que la vida útil de los sitios fortificados se prolongó por centurias. En el caso de América Latina las fortalezas

\footnotetext{
${ }^{1}$ Maestría en Historia de América Latina. goseder@ gmail.com
} 
construidas en tiempos virreinales pasaron de defender un sistema comercial transoceánico a ser bastiones de la soberanía de los nuevos estados nacionales durante el siglo XIX ${ }^{2}$.

En este largo periodo la artillería costera sufrió transformaciones importantes (aunque conservando sus atributos fundamentales), en un proceso en que los Estados estuvieron deseosos de acoplar a sus arsenales los desarrollos más modernos. Aun así, la historia de la artillería es escasamente abordada en la historiografía actual a pesar de que sus ecos se encuentran, más allá de los recintos militares o culturales, en la misma memoria urbana (en parques públicos o plazas conmemorativas). Todo ello, sin detenerse en darle la importancia que se merecen como bienes culturales parte de un patrimonio histórico militar.

Aún menos conocida es la evolución histórica de las cureñas que sostienen a las piezas, por lo que presenta un análisis más complejo para el historiador que pretenda abordarles a partir de restos arqueológicos o documentales. Centrándome en el caso del Baluarte de Santiago en la ciudad de Veracruz, a partir de una visita exploratoria realizada el día 24 de febrero de 2018, puedo afirmar que es posible llevar a cabo un estudio diagnóstico de alcance introductorio a fin de rastrear el tipo de sistema armamentístico en la cara sur del emplazamiento. Partiendo de los indicios arqueológicos en forma de cuña encontrados en la base de la batería de las colisas que se hallan en el adarve y los merlones a barbeta. Además, este estudio histórico se basa en historiografía internacional, fuentes documentales e integrando un análisis comparativo con sistemas fortificados similares. Sirviendo como base de una segunda etapa de investigación a futuro en que pueda profundizarse y ampliarse al resto del emplazamiento ${ }^{3}$.

\section{1.- La delimitación histórica de las cureñas y su artillería}

Como he señalado, los sistemas fortificados en las naciones hispanoamericanas tienen una larga historia de uso desde el siglo XVII al XIX. Dentro de este marco temporal los mecanismos que sostuvieron su artillería cambiaron de manera radical. Por desgracia, en la actualidad aún no existe una obra profunda o investigación exclusiva que aborde la Historia de las cureñas en México, por ello este estudio puede entenderse como pionero en el tema y tan solo como un primer acercamiento deductivo a fin de

\footnotetext{
${ }^{2}$ Este artículo está dedicado a la Administración Portuaria Integral de Veracruz (APIVER) quienes patrocinaron está investigación. Agradezco el apoyo y profesionalismo de la arquitecta Gladys Martínez Aguilar (Facultad de Arquitectura de la Universidad Veracruzana) y de la arqueóloga Judith Hernández Aranda (Instituto Nacional de Antropología e Historia/Veracruz). Esta investigación se enmarca dentro del Cuerpo Académico 233 "Tecnología e Historia Militar de México", Universidad Michoacana de San Nicolás de Hidalgo (México). Así como del grupo de investigación internacional CSG-Red Imperial, Universidad de Navarra (España).

${ }^{3}$ Una versión de esta investigación acotada solo al siglo XIX se presentó como ponencia en "McMullen Naval History Symposium" de la Academia Naval de Estados Unidos de América, Annapolis, Maryland, 20 de setiembre del 2019. Dicha versión preliminar aparecerá próximamente en la revista Derroteros del Mar del Sur de la Asociación de Historia Marítima y Naval Iberoamericana.
} 
aproximarse al objeto particular, que es conocer la tipología de determinada artillería del Baluarte de Santiago en Veracruz.

No obstante, ahondar en la historia del sistema de cureñaje de un país no solo tiene el fin de esclarecer algún tipo de armamento en un contexto determinado, retomando al historiador francés Emmanuel de Crouy-Chanel, bosquejar una historia de las cureñas muestra en última instancia un proceso de conformación del Estado moderno, posible gracias a la centralización de recursos destinados al sostenimiento de tecnología militar de punta en localidades estratégicas, que tenían como objetivo defender un régimen político ${ }^{4}$.

Este sería la meta final de una investigación profusa inductiva a futuro, por el momento tan solo se pretende delimitar a que temporalidad pertenecen los indicios hallados en el Baluarte de Santiago en Veracruz tras los trabajos de restauración de 2017. El también conocido como Baluarte de la Pólvora de Veracruz, se concluyó en 1635 bajo diseño del holandés Adrián Boot, fue erigido con el objetivo de repeler ataques de piratas y corsarios que desearan interrumpir el sistema mercantil monopólico que conectaba a la Nueva Veracruz (Nueva España) con la ciudad de Sevilla (España). Los cañones que poseyó durante sus primeras décadas de existencia con seguridad fueron piezas de bronce (culebrinas) fundidas en la Real fundición de Bronces del barrio de San Bernardo en Sevilla, que debían seguir los calibres de la ordenanza de artillería de $1609 .{ }^{5}$ Ya en 1695 Carlos Sigüenza y Góngora alababa la capacidad de fuego del Baluarte de Santiago "barriéndose con las piezas que están en sus troneras la Superficie del mar” y se pregunta ¿Qué embarcación enemiga se atreverá a acercarse sin que los artilleros le haga pedazos $?^{6}$

No obstante, ¿Qué sostenía a dichas piezas? La respuesta es la cureña, definida por la Real Academia de la Lengua Española como un armazón compuesto de dos gualderas fuertemente unidas por medio de teleras y pasadores, colocadas sobre ruedas o sobre correderas, y en la cual se monta el cañón. ${ }^{7}$ Una vez despejada la terminología básica, cabe preguntarse ¿Qué cureñas sostuvieron los cañones del Baluarte en sus diferentes momentos históricos? ¿A qué tipo pertenecen las marcas semicirculares halladas?

\footnotetext{
${ }^{4}$ Emmanuel de Crouy-Chanel, "Charroi de l'artillerie et construction de l'État moderne en France dans le dernier quart du XVe siècle" en Aude Mairey et al, "Contre-champs". Études offertes à Jean-Philippe Genet, Paris, Classiques Garnier, 2016, pp. 159-176.

${ }^{5}$ Quizá alguna pieza rezagada del antiguo modelo de 1533. Cabe aclarar que el peso de la bala del cañón determinada en el siglo XVI y XVII el calibre del armamento. La ordenanza de 1609 dictaba la fabricación de un gran cañón de 48 libras, el mediano de 24 libras, el denominado "cuarto de cañón" de 10 a 12 libras castellanas y el ligero de 5 a 6 libras. Hacia 1616 en la fortificación de San Diego de Acapulco se fundieron cañones de 24 libras y con seguridad piezas similares se ocuparon en los baluartes de Nueva Veracruz y San Juan de Ulúa. Biblioteca de la Secretara de la Defensa Nacional (BDN), S.a. "Comprehende las Ordenanzas que corresponden al real cuerpo de artillería e ingenieros. Árbitros aplicados a las obras de fortificación y academias de matemáticas para la tropa”, t. VI, en Colección General de Ordenanzas militares, sus innovaciones y aditamento, dispuesta en diez tomos, desde 1553 hasta 1758, Madrid, impresa por Antonio Marín por orden de José Antonio Portugués, 1765, pp. 54-55.

${ }^{6}$ Irving Leonard, "Informe de Don Carlos de Sigüenza y Góngora sobre el castillo de San Juan de Ulúa (1695)", En Revista de Historia de América, Núm. 45, 1958, p. 139

${ }^{7}$ Diccionario de la Real Academia de la Lengua Española, http://dle.rae.es/?id=BjIT5G6 (Consulta: 14/03/2018)
} 
Es necesario precisar que en los primeros tiempos de existencia del Baluarte de Santiago no se utilizaba la palabra "cureña" sino el término "encabalgamiento", tal como aparece en las fuentes primaras del periodo. ${ }^{8}$ Estos soportes eran de maderas como encinas (roble), álamo negro o blanco, olmo, fresno, nogal o pino. ${ }^{9} \mathrm{Su}$ fabricación corrió a cargo de carpinteros locales quienes trabajaron artesanalmente en cada pieza, pues no existió una normatividad que estandarizase los trabajos. Las cureñas durante esta primera etapa del Baluarte de Santiago variaron en sus dimensiones según el calibre de las piezas, pero no en su forma, siendo similares a las empleadas en las embarcaciones de la Carrera de Indias.

Esta situación continuó durante el siglo XVII hasta principios del siglo XVIII (ajustándose solamente su largo y ancho de la cureña a los calibres de la artillería según sus ordenanzas de 1718 y 1728) ¿Qué aspecto tenían? En el año 2015 el proyecto Cátedra de Historia y Patrimonio Naval (colaboración entre la Armada de España y la Universidad de Murcia) llevaron a cabo una recreación histórica de la cureña utilizada durante el periodo en las defensas fortificadas de la ciudad portuaria de Cartagena en España.

El mecanismo de movilización se basa en una solera, dos gualderas, dos ejes y cuatro ruedas de madera, siendo ligeramente de mayor tamaño las delanteras que las traseras. Este modelo continuó en uso, aunque mayormente en los navíos, al menos en la primera mitad del siglo XVIII como lo constata el "Diccionario demostrativo con la configuración y anatomía de toda la arquitectura naval moderna" de 1756, consultado en el Archivo del Museo Naval de Madrid.

Ilustración 1. Plano de cureña del Marqués de la Victoria, 1756

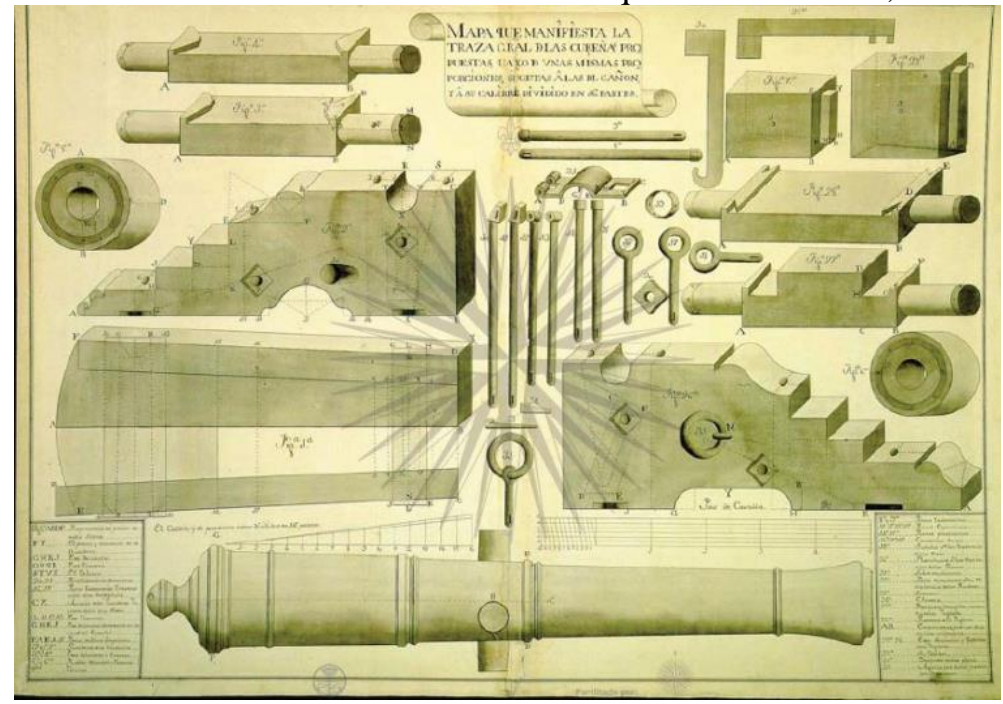

Archivo del Museo Naval de Madrid, Juan José Navarro, Diccionario demostrativo con la configuración y anatomía de toda la arquitectura naval moderna, Madrid, 1756, p. 90.

\footnotetext{
${ }^{8}$ Archivo General de Indias (en adelante AGI), Audiencia de México, 28, No.33, f.1

9 Tomas de Morla en 1784 señala que las mejores maderas para construir cureñas en el imperio español se hallaban en América. Tomás de Morla, Laminas pertenecientes al tratado de artillería que se enseña en el Real Colegio Militar de Segovia, edición facsimilar, vol. II, Segovia, Patronato del Alcázar de Segovia, 1993.
} 
Hacia la segunda mitad del siglo XVIII, específicamente, tras la aplicación de la Real Ordenanza de artillería de 1743 (inspirada en el sistema francés de Vallière de 1732) se procedió a estandarizar la artillería en cinco calibres. Menos conocido en la historiografía es que esta reforma a la tecnología militar hispana estandarizó el tipo de cureñas utilizadas hasta entonces en las "Plazas y Costas" de toda la monarquía ${ }^{10}$.

Si bien, el antiguo "sistema español" continuó en uso en los navíos de la Armada española, la influencia de la reforma francesa de la Vallière luego de 1743 modificó las cureñas en las fortificaciones costeras a ambos lados del Atlántico. Una descripción de la época, del año 1746, la aporta José Antonio de Villaseñor en su "Theatro Americano":

Santiago, que es el de la pólvora, está situado cerca del Mar, de la parte del Suest, y guarda el Canal, que viene de esta parte para el Puerto, y toda la Campaña, y Playa del Sur tiene montadas veinte, y quatro piezas, y dos culebrinas sobre el caballero alto, ay en el tres Almahacenes, donde se guarda la pólvora". ${ }^{11}$

Ilustración 2. Plano del Baluarte de Felipe León Maffey, 1728.

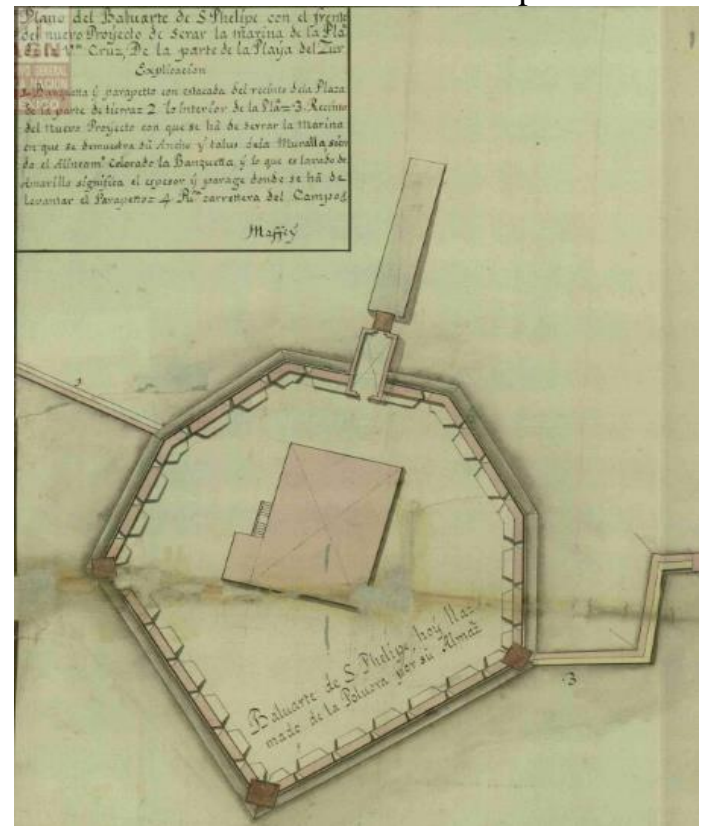

Archivo General de la Nación (en adelante AGN), Historia, vol.362, exp.1, f.228.

Para 1758 la plaza Veracruz (sin contar San Juan de Ulúa) disponía de 95 cañones de hierro y bronce pero solo funcionaban 29; el resto eran tan viejos

\footnotetext{
${ }^{10}$ La primera de estas reformas se dictó en noviembre de 1742 y concretó el diseño de 5 cañones de a 4, 8, 12, 16 y 24 pulgadas de calibre. Este sistema permitió una cadencia de fuego de un disparo por minuto. En realidad se redujo a implantar un sistema de artillería de sitio y campaña, constituido por una gama de piezas largas. AGI, Mapas, planos y dibujos, (años 1503-1805), vol. I, p. 261. Acompaña a carta de don Manuel García Campaña, Sevilla, 10 de abril de 1742, y a la Ordenanza de las proporciones que el Rey manda se observen uniformemente en sus fundiciones de España para la fábrica de la artillería.

${ }^{11}$ Joseph Antonio Villaseñor y Sánchez, Theatro Americano. Descripción General de los Reynos, y provincias de la Nueva España, y sus jurisdicciones, Impresora del Real y Apostólico Tribunal de la Santa Cruzada en todo este Reyno, México, 1746, p. 272.
} 
que resultaban inservibles, o eran de un calibre demasiado pequeño o no había municiones de su tamaño. ${ }^{12}$ ¿Qué cureñas sostuvieron dichas piezas? Situándonos en la región Caribe (a la que Veracruz se adscribe por la Carrera de Indias) existen indicios documentales de este tipo de cureña de Plaza costera al "estilo francés"; el plano de un modelo aplicado en San Juan de Puerto Rico en 1768 se ha localizado en el Archivo General de Indias, en Sevilla, España.

En las últimas décadas del siglo XVIII este tipo de cureña, que puede reconocerse su uso para plaza debido a sus ruedas macizas, sostuvo a los cañones emplazados en las fortificaciones de Veracruz, tanto en la fortaleza de San Juan de Ulúa como en los nueve baluartes de la muralla.

Ilustración 3. Cureña de Plaza para San Juan de Puerto Rico, 1768.

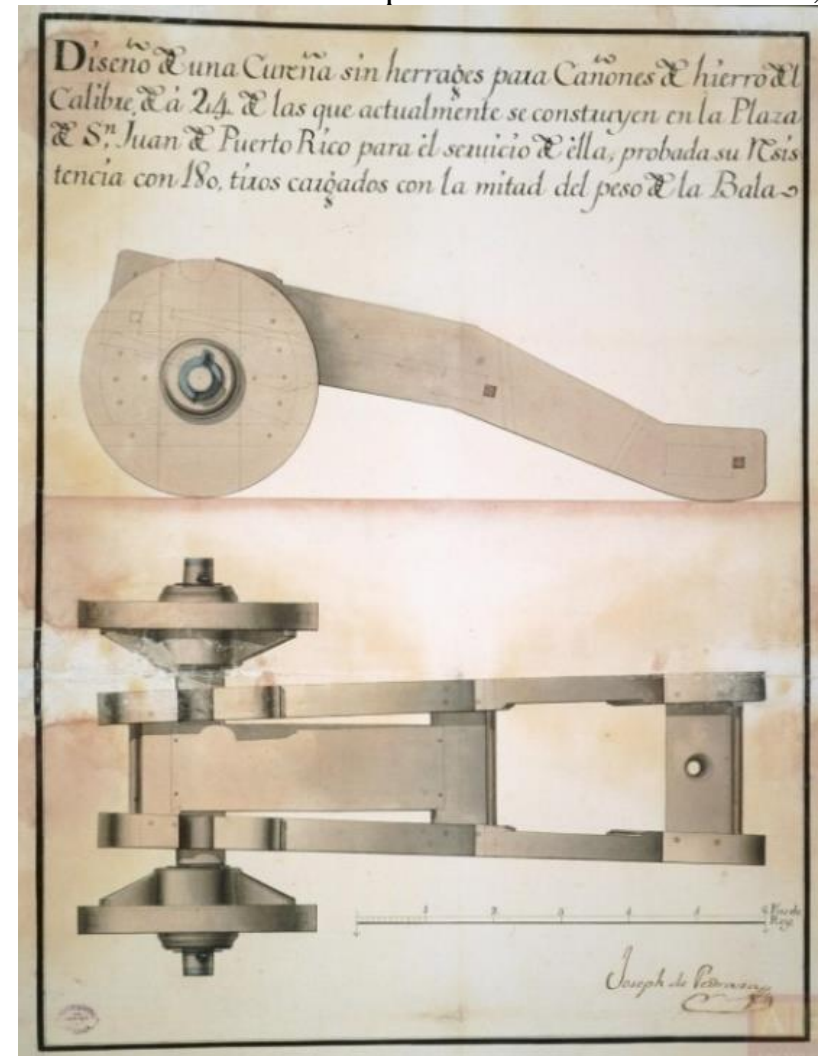

AGI, Mapas, planos y dibujos, Ingenios, 30.

Al menos se sabe que ese mismo año de 1768, con fecha 23 de noviembre, el virrey Marqués de Croix ordenó a los oficiales Reales apoyar en todo al Capitán de artillería de la plaza de Veracruz para la fabricación de estas cureñas. ${ }^{13}$ Posteriormente, hacia 1771 hay indicios de fabricación artesanal de cureñas para Veracruz en la ciudad de Puebla ${ }^{14}$; finalmente, a partir de

\footnotetext{
${ }^{12}$ Eder Gallegos, "La artillería novohispana ante el fantasma de invasión naval, 1762-1808", En Revista Tiempo y Espacio, Núm. 64, 2014, p.200.

${ }^{13}$ AGN, Gobierno Virreinal, Marina, 068, vol.27, exp.162, ff.373-376.

${ }^{14}$ AGN, Indiferente Virreinal, Caja 1-999/Caja 0618, 1771, exp.012, 10 ff. "Peticiones para mostrar fabricante de cureñaje en Puebla Oficial Segundo de Reales Aduanas en Veracruz",
} 
1778 se instaló una maestranza de artillería en la Fortaleza de San Carlos de Perote que se encargaría oficialmente de abastecer de afustes para los cañones destinados a la defensa de las costas del Golfo de México ${ }^{15}$.

En 1783 una nueva ordenanza de artillería (inspirada en el sistema francés de Gribeauval) introdujo mejoras en las cureñas, aligerando el peso y dotando de mayor maniobrabilidad, aunque sus mejoras se enfocaron principalmente en los montajes para cañones de campaña. Este tipo trascendió el periodo virreinal y se proyectó por varias décadas después del fin de la guerra por la independencia. Incluso el ejército mexicano utilizó cureñas de "Plaza y Costa" de este sistema durante el sitio de Puebla en 1863, mismas que se habían trasladado junto con sus cañones desde el puerto de Veracruz. ${ }^{16}$

La cureña de "Plaza y Costa" inspirada del sistema de Gribeauval debió continuar en uso durante las primeras décadas del México independiente en sitios como Veracruz. Dichas cureñas de "Plaza" presentaban un alto grado de rebote, por lo que requerían de mayor espacio dentro de murallas lo que reducía a su vez el campo de tiro, en partículas tenían el añadido de la dificultad de su transporte. ${ }^{17}$ Un modelo de dicho cureñaje junto con un cañón de 24 libras se exhibe actualmente en el Museo del Ejército de España y hasta 1910 se exhibió uno semejante en el porfiriano Museo Nacional de Artillería de México $^{18}$.

El estado del erario nacional después de la consumación de la independencia no permitió una reforma en los instrumentales artillados y sus monturas. De hecho, durante la primera década como país independiente México solo contó con 68 piezas funcionales. ${ }^{19}$ Esta crónica deficiencia a su vez explica la limitada efectividad de las defensas de Veracruz durante las sucesivas guerras de intervención extranjera. En la primera intervención francesa de 1838, los baluartes de la ciudad de Veracruz no representaron una amenaza para la potencia de fuego de la flota francesa que bombardeó del 27 de noviembre al 5 de diciembre de 1838 .

Un año antes de estos sucesos, Miguel Lerdo de Tejada, citando al General Manuel Rincón, describe en su obra "Apuntes Históricos de la Heroica ciudad de Veracruz" el estado en que se encontraban las cureñas de los baluartes de Veracruz en 1837, "Los baluartes estaban muy deteriorados; la artillería que había en ellos, estaba desmontada en partes, y otra parte estaba montada sobre

\footnotetext{
${ }^{15}$ AGN, Indiferente de Guerra. vol.276; 6 ff.

${ }^{16}$ Francisco del Paso y Troncoso, Diario de las operaciones militares del sitio de Puebla de 1863, Gobierno del Estado de Puebla, Secretaría de Cultura, Puebla, 1988, pp.41-44.

17 José María Esclus Gómez, Curso completo del arte y de la historia militar. Epitome de cuanto se ha escrito hasta el día sobre el arte de la guerra, Imprenta del Siglo a cargo de Ivo Biosca, Madrid, 1845, p.133

18 Tenía el número 13 de inventario. El modelo mexicano estaba construido en madera y era a escala de 1/5. Catálogo del Museo Nacional de Artillería, México, Talleres del Departamento de Estado Mayor, 1910, p.24; Ministerio de Defensa de España, ;No solo cañones!: Exposición temporal-Museo del Ejército. Madrid, Centro Geográfico del Ejército, 2014 , p.27.

${ }^{19}$ Dato ofrecido por el Dr. Ramón Alonso Pérez Escutia (Universidad Michoacana de San Nicolás de Hidalgo) en su sesión: "México independiente: la república federal", Diplomado en Historia Militar de México, Dirección de Estudios Históricos del INAH, 11 de abril de 2018.
} 
cureñas de buque o de plaza, y estás tan destruidas, que a los primeros tiros de las piezas habían de hacerse pedazos" ${ }^{20}$.

La capacidad de reacción de las bocas de fuego mexicanas era limitada desde un principio debido a la escasez de cureñaje y artillería adecuada en la plaza de Veracruz. En correspondencia, con fecha 11 de agosto de 1838, el General Manuel Rincón encargado de la defensa contra las hostilidades francesas, señala:

[...] el cureñage completamente destruido, conservándose solo en el baluarte de Santiago algunas piezas en regular estado para corresponder a los saludos que hacían los buques de guerra estrangeros, con la circunstancia de verificarse de tal manera los de la plaza, que tardaban más de tres cuartos de hora en disparar veinte y un $\operatorname{tiros}^{21}$.

De hecho, desde el inicio de hostilidades a la fortaleza de San Juan de Ulúa quedó patente la imposibilidad de auxilió de los baluartes de la ciudad: "los baluartes de Concepción y Santiago en la ciudad, que disparaban también sus tiros sobre los buques franceses, como para manifestar así, aunque inútilmente, su deseo de tomar alguna parte en aquel combate". ${ }^{22}$ Particularmente sobre las cureñas disponibles, el punto primero del "Acta formada por la Junta de Guerra" con fecha 28 de noviembre de 1838 señala: "no haber cureñaje de refacción, lo que ha disminuido notablemente la defensa"23.

Tras la resolución del conflicto con Francia era claro para el gobierno que el principal puerto de México no contaba con la tecnología adecuada para su defensa artillada. Según la revista militar, asentada con fecha 30 de noviembre de 1839, la mayoría de las piezas de los cañones de hierro y bronce, así como los obuses se encontraban desmontados al carecer de cureñas. Cabe recordar que por entonces en México solo existían cuatro sitios que, debido a la escases de recursos, fabricaban intermitentemente las cureñas para los cañones: las maestranzas de Ciudad de México, Campeche, San Luis Potosí y Veracruz; al tiempo que se discutía si reabrir la maestranza de la fortaleza de San Carlos en Perote ${ }^{24}$.

La "Memoria de Guerra y Marina" de 1840 indica que el gobierno del presidente Anastasio Bustamante designó al Director General de ingenieros, junto con jefes y oficiales del ejército, para realizar un reconocimiento de la plaza de Veracruz a fin de trazar un plan de obras para la mejora del sistema

\footnotetext{
${ }^{20}$ Miguel Lerdo de Tejada, Apuntes Históricos de la Heroica ciudad de Veracruz, Tomo II, México, Imprenta de Vicente García Torres, 1857, pp.405 y 406.

${ }^{21}$ Citado en José Bravo Ugarte, “El conflicto con Francia de 1829-1839”, En Historia Mexicana, Núm. 4, 1953 , p.492.

${ }^{22}$ M. Lerdo de Tejada, Apuntes Históricos de, p. 417.

${ }^{23}$ M. Lerdo de Tejada, Apuntes Históricos de, p.422.

${ }^{24}$ Memoria del Ministro de Guerra y Marina, presentada a las cámaras del Congreso General Mexicano, en Enero de 1840, México, Oficina el Águila, 1840, pp.16-17
} 
defensivo. ${ }^{25}$ Esta referencia es confirmada por documentación del Archivo General de la Nación donde ese año se solicita la aplicación del gobierno nacional a la reparación de los daños de San Juan de Ulúa. ${ }^{26}$ A su vez, la misma Memoria de Guerra y Marina de 1840 señala que se contratará en Inglaterra, a través del Ministro Plenipotenciario de México en Londres, a un fabricante para la adquisición de cañones, con seguridad de hierro colado:

El gobierno está empeñado en llevar al cabo la construcción de armas de fuego de todos los calibres, al estilo de las inglesas y francesas, siempre que para verificarse puedan admitirse legalmente las propuestas que desde Europa se le dirigieron por conducto del ministro plenipotenciario de la república en Londres. La dirección de artillería, después de haber oído a la junta facultativa del cuerpo, ha recomendado eficazmente las propuestas para que se realice la contrata $[. .$.$] cree que por medio de la contrata se mejorara muy$ pronto la artillería mexicana, no dudando que luego de que se celebre se comenzará a establecer en esta Capital, un conservatorio de piezas de todos los calibres, á ejemplo del que existe en Inglaterra $^{27}$.

Para ese momento la artillería que disponía la plaza de Veracruz (que comprendía todos sus baluartes) contaba con un total de tan solo 8 cañones y 4 obuses. 1) Cañones: 3 de bronce de calibre de 14, dos de bronce y dos de hierro de a 9, 1 de bronce de a 8;2) Obuses: 2 de bronce de calibre de a 7 y dos de bronce de calibre de a $4^{28}$.

¿Qué sucedió con el plan de 1840? El divulgador Mario Gaspar Covarrubias sostiene que a partir de 1842 -durante el gobierno de Antonio López de Santa Anna- se realizó la mejora estructural del Baluarte de Santiago planificada desde la administración de Bastamente. Sin embargo, señala que la artillería que se alojó desde entonces eran "cañones ingleses giratorios Vickers". ${ }^{29}$ Esta aseveración es incorrecta dando que el fabricante inglés Vickers, Sons \& Company no fabricó su primer pieza de artillería sino hasta 1890, antes de este periodo solo de dedicó a la fundición de campanas para iglesias, piezas de acero para buques como hélices de propulsión y placas para blindaje naval $^{30}$.

A pesar del error del divulgador, certero resulta que entre marzo de 1842 y octubre de 1843 (entre los gobiernos de Antonio López de Santa Anna y Nicolás Bravo) se adquirió artillería inglesa y además cureñas del tipo

\footnotetext{
${ }^{25}$ Memoria del Ministro, p.26

${ }^{26}$ AGN, Guerra y Marina, 140, Ministerio de Estado y Despacho de Guerra y Marina, Caja 48, exp.10

${ }^{27}$ Memoria del Ministro, pp.14 y 15.

${ }^{28}$ Memoria del Ministro, Anexo número 12.

${ }^{29}$ Mario Gaspar Covarrubias, "El baluarte de Santiago y los 500 años de fundación de la actual ciudad de Veracruz", https://efacico.wordpress.com/2017/10/10/el-baluarte-de-santiago-y-los-500-anos-de-fundacion-de-la-actual-ciudad-deveracruz/ (Consulta: 24/03/2018)

30 Véase, Alex Richardson, Vickers, Sons and Maxim, Limited: Their Works and Manufactures, Londres, Offices of "Engineering", 1902, 166 pp; actualmente el archivo histórico de la empresa se encuentra en la biblioteca de la Universidad de Cambridge, su documentación abarca el periodo de 1830 a 1980 : https://archiveshub.jisc.ac.uk/search/archives/8906e45d-9675-3e3a-ac64-be3c116b382d (Consulta: 16/04/2018)
} 
anglosajón para la fortaleza de San Juan de Ulúa y la Plaza de Veracruz, incluyendo al Baluarte de Santiago:

Tabla 1. Artillería inglesa adquirida para Veracruz por el Gobierno de México a través de Manuel Escandón. Relación con fecha 17 de diciembre de 1843. ${ }^{31}$

\begin{tabular}{|l|c|c|c|c|c|c|c|}
\hline & \multicolumn{2}{|c|}{ Cañones bomberos } & \multicolumn{2}{|c|}{ Cañones } & Morteros & Obuses & $\begin{array}{c}\text { Montaje } \\
\text { s }\end{array}$ \\
\hline & $\begin{array}{c}\text { De a 10 } \\
\text { pulgadas } \\
\text { inglesas }\end{array}$ & $\begin{array}{c}\text { De a 8 } \\
\text { pulgadas } \\
\text { inglesas }\end{array}$ & $\begin{array}{c}\text { De a } \\
12\end{array}$ & $\begin{array}{c}\text { De } \\
\text { a 8 }\end{array}$ & $\begin{array}{c}\text { De a 12 } \\
\text { pulgadas } \\
\text { inglesas }\end{array}$ & $\begin{array}{c}\text { De a 8 } \\
\text { pulgadas }\end{array}$ & $\begin{array}{c}\text { De todas } \\
\text { clases }\end{array}$ \\
\hline Contratado & 10 & 10 & 6 & 10 & 6 & 6 & 82 \\
\hline Recibido & 10 & 10 & 5 & 10 & 6 & 6 & 56 \\
\hline Faltan & n/a & n/a & 1 & n/a & n/a & n/a & 26 \\
\hline
\end{tabular}

Fuente: Memoria del Secretario de Estado y del Despacho de Guerra y Marina, leída a la cámara del Congreso Nacional, México, Impresa por Ignacio Cumplido, 1844, Anexo Número 18.

El objetivo era modernizar el sistema defensivo costero con base en los nuevos avances en artillería de costa desarrollados en Europa. Hasta el momento el sistema de cureñaje implicaba el movimiento hacia delante y hacia atrás del ánima a través de ruedas y un eje (este mecanismo en esencia era similar desde los albores de la artillería) por fin tuvo su mayor revolución al desarrollar un marco con ruedas dentadas para dotar de un radio de acción de 90 grados al horizonte, con la meta triplicar la capacidad de un cañón naval $^{32}$.

Para poner contexto, en España los primeros sistemas de cureñas sobre marcos giratorios se introdujeron en las costas en 1844 (un año después de la presunta adquisición del baluarte de Santiago). Se trataba de un conjunto formado por dos brancales (largueros) fabricados en madera con una inclinación, conectado mediante varios travesaños y sobre estos se colocaba la cureña de la pieza. El marco poseía un eje que le permitía un giro horizontal y unas ruedas en la parte inferior para dirigir la pieza para disparar contra un blanco móvil. A partir de este momento el sistema se dividió en dos versiones: los de marco bajo para piezas en casamata y los de marco alto para piezas a barbeta $^{33}$. Un ejemplar bien conservado de estos primeros prototipos de marcos de madera de costa se encuentra en el Museo del Ejército, en la ciudad de Toledo, España ${ }^{34}$.

De regreso a las costas del Golfo de México, la "Memoria de Guerra y Marina" de 1844 arroja más datos sobre las piezas que se introdujeron en las fortalezas costeras de Veracruz. El primer contrato se efectuó bajo el Misterio de Guerra y Marina de José María Tornel, el 8 de marzo de 1842, y no solo

${ }^{32}$ Germán Guía, “La artillería costera rayada en Venezuela: Innovación tecnológica en la Regeneración Guzmancista (18751876)", en Revista Tiempo y Espacio, Núm.67, 2017, p.101

${ }^{33}$ Ministerio de Defensa de España, ¡No solo cañones!: Exposición temporal-Museo del Ejército. Madrid, Centro Geográfico del Ejército, 2014, pp.38 y 39

${ }^{34}$ Ministerio de Defensa de España, ¡No solo cañones!, p.46. 
involucró a Manuel Escandón sino también al empresario minero Juan Manuel Lasqueti, quienes gestionaron la adquisición de los 74 cañones de diversos calibres "debiéndoseles pagar su importe desde luego con un 5 por 100 de los derechos de importación de los puertos de Tampico y Veracruz, é hipotecándoles además todos los fondos y terrenos de parcialidades". El apunte señala que el contrato para los montajes de artillería se realizó después del 23 de marzo de 1843, adquiriendo en total 26 a un precio de 1200 pesos por cada uno.

Posteriormente se hizo otro nuevo contrato con Manuel Escandón para 7 cañones tipo bomberos (denominados también Paixhans que arrojaban munición hueca o bomba) de a 10 pulgadas a un costo de 3000 pesos cada uno, 7 cañones bomberos más de a 8 pulgadas a 3000 pesos cada uno, 50 cañones de a 24 a 2000 pesos cada uno. Esto incluía la compra de 64 cureñas para las mencionadas piezas a 1200 pesos cada una. En una concesión privilegiada del Gobierno a Escandón pues poseía "permiso de embarcar en uno o más buques 100000 pesos sin pagar los derechos de exportación"35.

Ilustración 4. Cañón bombero (Paixhans) en cureña francesa de costa.

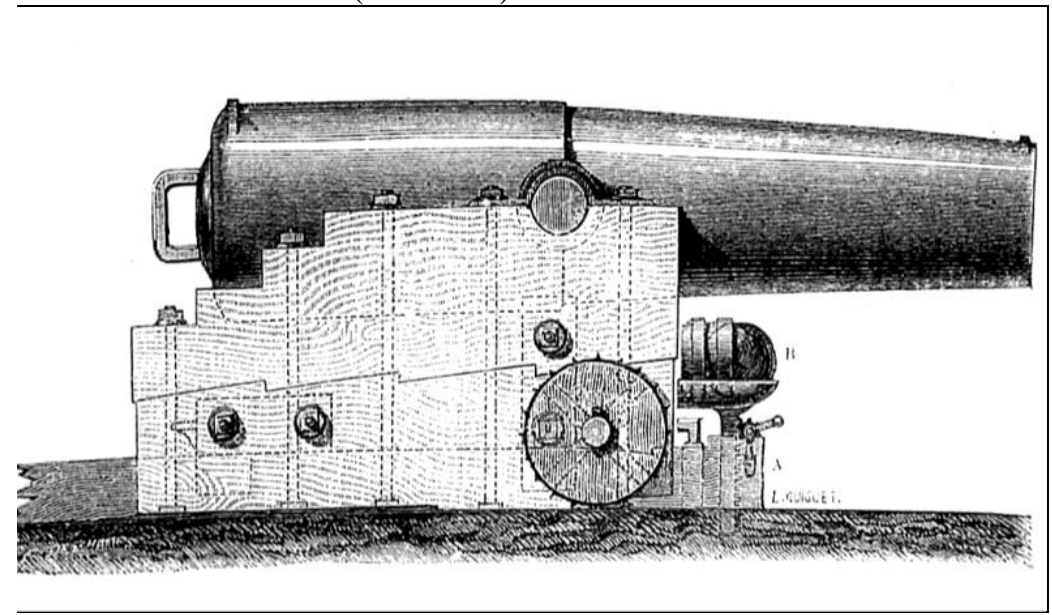

Musée de l'Armée (Museo del Ejército de Francia, Paris).

¿Cuál era la importancia de esta artillería de costa? ¿Cuál es la relevancia de contar con piezas que arrojen bombas? En 1845 el comandante español José Esclus Gómez, en su obra Curso completo del arte e historia militar, deja en claro la relevancia de las baterías de costa y de contar con los por entonces nuevos avances en artillería.

Las baterías de costa son las establecidas á la orilla del mar, con objeto de oponerse á los desembarcos del enemigo, en la extensión que ellas dominan, y de proteger la navegación comercial de la potencia que las ha establecido contra las fuerzas marítimas de la potencia enemiga [...] Bastante se ha escrito sobre la utilidad de estas fortalezas, y de que en ellas se montasen también algunos morteros: y efectivamente, si bien es

\footnotetext{
${ }^{35}$ Memoria del Secretario de Estado y del Despacho de Guerra y Marina, leída a la cámara del Congreso Nacional, México, Impresa por Ignacio Cumplido, 1844, Anexo Número 14, II.
} 
difícil echar una bomba dentro de un buque, sobre todo si se halla á la vela, en caso de acertarlo su perdida sería inevitable, y ya se sabe cuán adelantado está e acierto del tiro de las bombas entre los actuales $\operatorname{artilleros}^{36}$.

Específicamente sobre los cañones Paixhans, desde 1830 la Cartilla de artillería de Marina para el uso de los guardias marinas, del español Francisco Ciscar, deja en claro la potencialidad de esta tecnología:

$1^{\mathrm{a}}$. Pueden tirarse bombas horizontalmente lo mismo que balas, sin gran dificultad en el servicio.

$2^{a}$. Los cañones bomberos serán desde luego de una gran utilidad en las costas y aun en las lanchas cañoneras.

$3^{\text {a }}$. Su efecto contra los buques es tan terrible que uno ó dos tiros aprovechados sacarán de combate y aun echarán á pique un navío de alto bordo $^{37}$.

Las piezas y cureñas adquiridas por el gobierno mexicano a través de Manuel Escandón se recibieron en diferentes momentos a lo largo de marzo de 1842 y prolongándose hasta 1846. Sin embargo, no todo este instrumental se destinó a la plaza de Veracruz y tampoco fue una solución tecnológica adecuada pues cabe la sospecha de corrupción en los mecanismos de adquisición y malos manejos de los fondos. Desde 1844, el Teniente Coronel de artillería Bruno Aguilar y un grupo de jefes facultativos del cuerpo de artillería expusieron al gobierno nacional que notaban defectos en la fabricación de los proyectiles y la artillería, pero "el Gobierno a pesar de esto, se hizo cargo de todo, y en el día está haciendo uso de uno y otro en las fortalezas a que se determinaron" 38 .

Tampoco haberlo recibido no significó que se colocaran inmediatamente, pues las convulsas circunstancias políticas de la primera mitad del siglo XIX requerían poner foco en prioridades internas. Por ejemplo, al año siguiente de 1845 estalló el movimiento de Mariano Arista que desconoció el mandato de Antonio López de Santa Anna. La misma "Memoria de Guerra y Marina" de ese año es reflejo de trastornos pues comienza con un estado minucioso de la situación política y los movimientos al interior. Más adelante detalla que en los baluartes de la plaza de Veracruz había cañones de hierro y bronce de 24 libras, de hierro de a 18, de hierro y bronce de a 16, mayor cantidad de hierro y bronce de a 12 , de hierro y bronce de a 6 y 4 libras de calibre, culebrinas de bronce de a 4 , morteros de a 12 de bronce, obuses de a 8 de bronce, obuses de a 7 y de a 4 libras de bronce. ${ }^{39}$ Esto es un claro ejemplo de la enorme variedad de piezas que componían la dotación de los baluartes. Si bien, como

\footnotetext{
${ }^{36}$ José María Esclus Gómez, Curso completo del arte y de la historia militar. Epitome de cuanto se ha escrito hasta el día sobre el arte de la guerra, Madrid, Imprenta del Siglo a cargo de Ivo Biosca, 1845, p. 142.

${ }^{37}$ José Ciscar, Cartilla de artillería de Marina para el uso de los guardias marina, Madrid, Imprenta Real, 1830, p.135

${ }^{38}$ Memoria del Secretario de Estado y del Despacho de Guerra y Marina, leída a la cámara del Congreso Nacional, Impresa por Ignacio Cumplido, México, 1844, Anexo Número 14, II.

${ }^{39}$ Memoria del Secretario de Estado y del Despacho de Guerra y Marina, leída a la cámara del Congreso Nacional, Impresa por Ignacio Cumplido, México, 1845, Anexo Número 8.
} 
advierte en la nota $2^{\mathrm{a}}$ de la lámina 8 , con fecha 22 de febrero de 1845 : "la mayor parte de la artillería que figura está desabocardada y los montajes necesitan varias recomposiciones, y muchos de ellos construirse de nuevo" 40 .

A este panorama desalentador debió sumarse la emergencia nacional producto de la guerra entre México y Estados Unidos desde mediados de 1846. En números generales, para ese mismo año de los 168 cañones ingleses de hierro que debieron introducirse, solo había llegado 104 debido al bloqueo naval de EE.UU. y la neutralidad que debió mantener Inglaterra. Tal situación reactivó temporalmente la fabricación nacional de artillería. ${ }^{41}$ La plaza de Veracruz meses antes de la invasión norteamericana de marzo de 1847 contaba con 144 piezas de artillería y de las cuales más de una tercera parte (55 piezas) se encontraban aún desmontadas sin cureña. ${ }^{42}$ Esta era la situación de la defensa cuando el 9 de marzo de 1847 las tropas norteamericanas bajo el comando de Winfield Scott comenzaron a asediar el puerto. A inicios del episodio, la propia población porteña tuvo que recaudar fondos para el reparo inmediato de cureñas en San Juan de Ulúa mientras que en los baluartes de la plaza, como el de Santiago, la mayoría de las piezas empotradas no estaban en las cureñas adecuadas. Miguel Lerdo de Tejada lo retrata de la siguiente manera:

difícil que sería conservar el honor nacional, faltándoles como les faltaban todos los medios necesarios para la defensa, hasta el grado de que fuera indispensable el donativo de unos cuantos ciudadanos para que pudiese componerse y conservarse el cureñaje de la fortaleza de Ulúa [...] Examinemos cuáles eran los medios de defensa en los baluartes. Cañones de 24 [pulgadas de calibre] montados en cureñas de á 18 y éstos en las de á 12, y aun de éstas, varias en un estado inútil por la falta de herrajes, su vejez y el abandono en que habían estado ${ }^{43}$.

Aunque si se habían colocado los "cañones bomberos" en el Baluarte de Santiago, con seguridad no sucedió lo mismo con las cureñas adquiridas en Inglaterra. Tanto las "Memorias de Guerra y Marina" como los Apuntes Históricos de Lerdo de Tejada coinciden en el ruinoso estado de sus montajes, pero al menos esta última fuente indica que el Baluarte tenía el poder fuego suficiente para ofrecer una defensa seria:

El fuego continuaba el 23 [de marzo de 1847]: remolcados unos buques hasta frente á los Hornos por el vapor Mississipí; aquellos y éste rompieron sobre la ciudad el fuego con sus cañones bomberos. Ulúa y el baluarte de Santiago les contestaron con los suyos y los

\footnotetext{
${ }^{40}$ Memoria del Secretario, Anexo Número 8.

${ }^{41}$ Se ideó erigir una fundición de cañones junto a la fábrica de pólvora de la Ciudad de México "junto al punto de Chapultepec, Memoria del Secretario de Estado y del Despacho de Guerra y Marina, leída a la cámara del Congreso Nacional, Impresa por Ignacio Cumplido, México, 1846, p.25

${ }^{42}$ Memoria del Secretario de Estado, Anexo Número 11.

${ }^{43}$ Miguel Lerdo de Tejada, Apuntes Históricos de la Heroica ciudad de Veracruz, Tomo II, Imprenta de Vicente García Torres, México, 1857, pp.507 y 509.
} 
desalojaron, precisándolos á retirarse, por el acierto con que se les correspondieron ${ }^{44}$.

Hacia el día 26 de marzo de 1847, en los momentos finales del asedio a Veracruz, las fuerzas defensoras se habían quedado sin parque, mientras que sufrían "la imposibilidad de reponer multitud de cureñas rotas, y de cañones fuera de combate, [que] vienen á completar este cuadro de devastación". ${ }^{45} \mathrm{La}$ guerra de intervención norteamericana fue un duro golpe para las instituciones armadas en México pero exhibió la necesidad de introducir reformas urgentes en los sistemas tecnológicas y en las formas de producción. Al siguiente año luego del fin de la guerra, en 1849 se adoptó el sistema francés de artillería. Este se basaba en piezas de campaña de 8 de a 12 y obuses de 24. Particularmente, con respecto a la artillería de la plaza de Veracruz refiere la Memoria de 1849 que debían dotarse los baluartes de Santiago y la Concepción con las piezas de San Juan de Ulúa pues "los fuegos del castillo, que lejos de defenderla, la amenaza"46.

Tabla 2. Piezas de artillería existentes en los baluartes de la Plaza de Veracruz, 1849

\begin{tabular}{|l|c|}
\hline \multicolumn{1}{|c|}{ Calibre de piezas } & Cantidad \\
\hline Cañón de a 68 libras (bomberos) & 6 \\
\hline Cañón de 42 libras (bomberos) & 6 \\
\hline Cañón de 24 libras & 17 \\
\hline Cañón de 22 1/2 libras & 6 \\
\hline Cañón de 18 libras & 1 \\
\hline Cañón de 16 libras & 16 \\
\hline Cañón de 12 libras & 10 \\
\hline Cañón de 8 libras & 14 \\
\hline Cañón de 6 libras & 8 \\
\hline Cañón de 4 libras & 3 \\
\hline Mortero de a 11 pulgadas & 11 \\
\hline Mortero de a 13 pulgadas & 6 \\
\hline Mortero de a 12 pulgadas & 5 \\
\hline Mortero de 9 pulgadas & 3 \\
\hline Mortero de a 8 pulgadas & 1 \\
\hline
\end{tabular}

Fuente: Memoria del Secretario, Anexo número 19.

Comparando este material con fecha 1849 con el que se había adquirido seis años atrás se notan diferencias importantes. Es posible que algunos de los cañones adquiridos para Veracruz en la contrata con Manuel Escandón permanecieran tras el conflicto en el Baluarte de Santiago, pero es muy probable que piezas más llamativas fueron tomadas como botín de guerra por el Marina de guerra de Estados Unidos de Norteamérica, en la actualidad

\footnotetext{
${ }^{44}$ M. Lerdo de Tejada, Apuntes Históricos de, p. 517.

${ }^{45}$ M. Lerdo de Tejada, Apuntes Históricos de, p. 521.

${ }^{46}$ Memoria del Secretario de Estado y del Despacho de Guerra y Marina, leída a la cámara del Congreso Nacional, Imprenta de Vicente García Torres, México, 1849, p. 22.
} 
algunas piezas tomadas en Veracruz durante 1847 se exhiben en el Washington Navy Yard como bien lo ha documentado John L. Morris del Springfield Arsenal ${ }^{47}$.

La pérdida de artillería mexicana tras la guerra dejaba solamente dos líneas de acción: 1) efectuar nuevos contratos de adquisición de armamento con naciones extranjeras a través de intermediarios particulares 2) impulsar una producción nacional. La primera opción había sido claramente ineficiente ante la demora de los envíos y la fragilidad del abasto de sufrir un bloqueo naval enemigo, la segunda parecía más viable como un plan de desarrollo estratégico del presidente José Joaquín Herrera, así lo apuntaba la "Memoria del Secretario de Estado y del Despacho de Guerra y Marina" en 1850: "El recuerdo del conflicto en que se vio la República en la última guerra: bloqueados todos los puertos, no se pudo introducir el armamento que tanta falta hacía para defender la dignidad nacional. Una fábrica de armas es necesaria á todo el país" ${ }^{48}$.

En cuanto a las cureñas, por entonces se mantenía la producción en la lejana ciudad de Monterrey y en la maestranza de Molino del Rey en ciudad de México. En esta última se empezó a activar un horno para la fundición de cañones junto con las máquinas para tornear y barrenar las ánimas, de tal manera que "muy pronto se verán regularizados los trabajos de fundición; de modo que lo esté nuestra artillería" 49 .

Este panorama de una futura producción nacional de artillería resultaba esperanzador, pero no sucedía lo mismo con el estado de las fortificaciones costeras en Veracruz dado que no había recursos económicos destinados a su reparo. El propio Ministro de Guerra Mariano Arista plasmó en sus memorias "no es honor de la República el que sus fortalezas estén desmanteladas y los montajes de la artillería inútiles en su mayor parte", señala que el presupuesto era insuficiente y solicitaba "si al gobierno se le faculta para disponer de cien mil pesos, hará una reparación muy considerable en las fortalezas" 50 .

La documentación histórica de la Secretaría de Estado y del Despacho de Guerra y Marina muestra que en el periodo entre 1849 y 1851 en los baluartes de Veracruz gradualmente se sustrajeron morteros y se sustituyeron por cañones. Empero. Una cosa es tener la artillería a disposición y otra diferente es contar con los adecuados montajes para darles un uso correcto. Al año siguiente de 1851 comenzó la producción de la fundición nacional de artillería

\footnotetext{
${ }^{47}$ Es probable que las piezas más potentes en la época fuera reutilizadas por las fuerzas estadounidenses en otros conflictos, mientras que las piezas históricas se resguardaran como curiosidades militares. En la actualidad se exhiben en el Washington Navy Yard cañones de bronce del siglo XVIII fabricados en Sevilla y Barcelona que fueron tomados durante las operaciones de 1847 en Veracruz y Antón Lizardo.

${ }^{48}$ Memoria del Secretario de Estado y del Despacho de Guerra y Marina, leída a la cámara del Congreso Nacional, Imprenta de la calle de Medina México, 1850, pp. 52-53.

${ }^{49}$ Memoria del Secretario, p. 51.

${ }^{50}$ Memoria del Secretario de Estado y del Despacho de Guerra y Marina, leída a la cámara del Congreso Nacional, México, Imprenta de la calle de Medina, 1850, p. 54.
} 
en la ciudad de México ${ }^{51}$, mientras que en los baluartes de Veracruz el número de cañones había disminuido a 109 piezas. Aún más relevante es el dato que de este total tan solo 36 piezas estaban montados en cureñas y 76 estaban inútiles por carecer de medios en que sostenerse para disparar. ${ }^{52}$ Por otra parte, puede apreciarse en las fuentes del periodo un proceso gradual, en los baluartes de Veracruz se mantenía el número de morteros y cañones bomberos pero anualmente se disminuía drásticamente el número de cañones.

El punto importante en el desarrollo de la artillería mexicana y su impacto en las defensas costeras del Golfo fue en el año de 1852. En la ciudad de México se concluyó la primera fundición de 18 nuevas piezas de bronce y la fabricación de 41 cureñas de varios calibres, al tiempo que se estableció con este mismo objetivo "un taller en Veracruz para ejecutar las más importantes con tanta actividad cuanta sea posible" con el fin de mantener el sistema de cureñas de las 92 piezas con que contaba por entonces la plaza. ${ }^{53}$ Este taller refiere a la reactivación de la maestranza de artillería de Veracruz (cercana al Baluarte de Santiago) destinada a la composición y reparo de las cureñas de los cañones ${ }^{54}$. En adelante este sitio será el encargado de manufacturar y reparar las cureñas destinadas a la fortificación de San Juan de Ulúa y los baluartes de la plaza de Veracruz.

Los gobiernos liberales estuvieron interesados en incentivar la producción nacional de artillería y cureñas para evitar la dependencia al extranjero, aunque los gobiernos conservadores contuvieron esta política a la tecnología militar y con ello introdujeron piezas mediante cuestionables convenios. Tras el retorno de Antonio López de Santa Anna, en abril de 1853, de nueva cuenta se efectuó un contrato entre el gobierno nacional y Manuel Escandón para la compra de cureñas de fabricación norteamericana por un valor de 234.957,60 pesos. Esto según la correspondencia entre el proveedor Carlos Butterfield \& $\mathrm{CO}$ y el cónsul mexicano en Nueva Orleans Francisco de Paula Arraingoiz, con fecha 22 de septiembre de 1854, documentación que se encuentra en el Acervo Histórico Diplomático de la Secretaria de Relaciones Exteriores de México $^{55}$.

La efervescencia política liberal del Plan de Ayutla -el 1 de marzo de 1854y la posterior movilización armada del "Ejercito Restaurador de la Libertad"

\footnotetext{
${ }^{51}$ Memoria del Secretario de Estado y del Despacho de Guerra y Marina, leída a la cámara del Congreso Nacional, México, Imprenta de Vicente García Torres, 1851, p. 29

${ }^{52}$ La diferencia de números indica que probablemente entre 1849 y 1851 se sustrajeron morteros y se agregaron cañones en los baluartes. Los calibres se mantuvieron semejantes a los registrados en la Tabla II. El número de cañones era de 90 con calibres de 68, 42, 24. 22, 16, 12, 8 y 4. Mientras que morteros eran 19 con calibres de 13, 12, 9 y 8. Memoria del Secretario, Anexo número 9

${ }^{53}$ Para 1852 se contaba a detalle con 12 cañones bomberos de a 68 y 6 de a 42 de calibre. Cañones eran 32 de a 24,4 de a 22, 16 de a 16, 3 de a 12 de calibre. Mientras que morteros eran 6 de a 13, 5 de a 12, 6 de a 9 y 2 de a 8 . Memoria del Secretario de Estado y del Despacho de Guerra y Marina, leída a la cámara del Congreso Nacional, México, Imprenta de Vicente García Torres, 1852, p.10 y Anexo número 9.

${ }^{54}$ Dicha maestranza de artillería es bien descrita en los Apuntes históricos de Miguel Lerdo de Tejada. Esta referencia a la reactivación de 1852 se conjunta con los indicios a actividades antecesora sobre 1840. Sin embargo, me queda la duda sobre la existencia de una primera maestranza de artillería en funciones desde tiempos virreinales y que probablemente ocupó una distinta sede (actual Museo de la ciudad de Veracruz).

${ }^{55}$ Los primeros consulados de México 1823-1872, México, Secretaría de Relaciones Exteriores, 1974, pp.29-30.
} 
encabezado por Juan Álvarez; inició una nueva etapa en el destino de la artillería y los pilares institucionales de México. Con el triunfo de la Revolución de Ayutla arribó una nueva generación de políticos liberales como Ignacio Comonfort, Benito Juárez y Melchor Ocampo- con una visión distinta del Estado y de su administración.

El 5 de febrero de 1857 entró en vigor la nueva Constitución de corte liberal, este plan de Estado iba acompañado de propuestas en distintos ramos de la administración como la defensa militar. Ese mismo año el Coronel de Ingenieros D.J Palafox dirigió un proyecto para la mejora de las defensas de la plaza de Veracruz, mismo que comprendió: "Un retrincheramiento enfrente del baluarte de Santiago, conteniendo una batería hacia el mar, y otras defensas hacia la parte de tierra" 56 .

¿Este es el momento en que se colocaron en el Baluarte de Santiago los montajes móviles para cureñas de costa? Resulta escasamente probable puesto que, sorprendentemente, para el año de 1857 la cantidad de artillería disponible en todos los baluartes de Veracruz se había disminuido dramáticamente a 3 cañones de calibre de a 8 libras y 3 obuses de 24 libras de calibre ${ }^{57}$. No obstante, que la Memoria de Guerra y Marina de ese mismo año reafirma que el presidente Ignacio Comonfort (1855-1857) impulsó obras de reparo de las fortificaciones costeras de Veracruz y la modernización de sus piezas de artillería ${ }^{58}$.

A pesar de esta afirmación, al poner atención a los detalles presentados en las dos primeras litografías de Veracruz que realizó Casimiro Castro entre 1855 y 1869 aproximadamente. Ambas son idénticas salvo algunos cambios menores (como el agregado de vegetación en la plaza de armas) y fueron publicadas respectivamente dentro del libro México y sus alrededores. Colección de vistas y monumentales, paisajes y trajes del país en las ediciones de $1855-1856$ y $1869^{59}$.

En el periodo comprendido en la elaboración de las litografías sucedieron convulsiones armadas que requirieron la atención primordial del erario nacional, me refiero a la intestina Guerra de reforma (1858-1861) y la Segunda intervención francesa (1862-1867). Así, resulta difícil que en este lapso se emprendiera una reforma importante a los sistemas artillados en Veracruz. En los detalles de las litografías de Casimiro Castro, centrándome en los Baluartes de la Concepción y de Santiago, no se observan marcas pertenecientes a rieles de modernos montajes de costa, aunado a lo anterior

\footnotetext{
${ }^{56}$ M. Lerdo de Tejada, Apuntes Históricos de, p.43

${ }^{57}$ Memoria del Ministerio de Guerra y Marina, presentada al primer Congreso Constitucional de 1857, Imprenta de Juan B. Navarro, 1857, Anexo número 12.

${ }^{58}$ Memoria de Ministerio, p. 124.

${ }^{59}$ La edición de 1855-1856 de la obra México y sus alrededores. Colección de vistas y monumentales, paisajes y trajes del país fue consultada gracias al acervo digital de la Universidad Autónoma de Nuevo León: http://cdigital.dgb.uanl.mx/la/1020006656/1020006656.PDF (Consulta 18/04/2018); por su parte, la edición de 1869 se consultó gracias al acervo digital de la New York Digital Library: https://digitalcollections.nypl.org/collections/mxico-ysus-alrededores-coleccion-de-vistas-monumentales-paisajes-y-trajes-del\#/?tab=about (Consulta 18/04/2018).
} 
destaca notar una escasez de artillería tal como se registró poco antes del inicio de conflicto entre liberales y conservadores en las Memorias de Guerra y Marina.

Ilustración 5. Litografías de los Baluartes de Concepción y Santiago, 1855-1869.

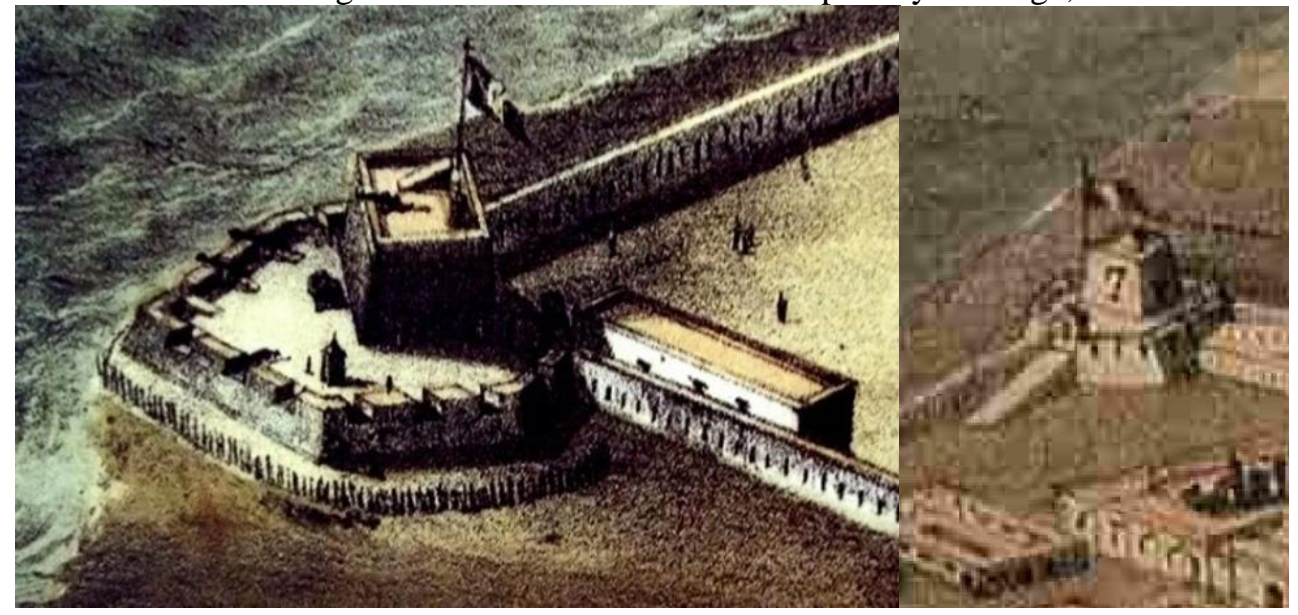

Resulta más certero buscar la modernización de los montajes móviles y de su artillería en los primeros años de la República restaurada y más allá. La subsecuente Memoria de Guerra de 1869 da cuenta del reciente restablecimiento de la maestranza para las cureñas de artillería en el edificio de la Ciudadela en ciudad de México y que de ella:

deberá surtirse del material de guerra correspondiente, á todos los puntos de la Republica que lo necesiten. Con esta medida se evita la planteación de otros establecimientos que, aunque en menor escala, existían ántes, tales como los de Tampico, Monterrey y Veracruz, que elaboraban un material de guerra que no quedaba bien construido [...] De paso sebo manifestar que sería muy conveniente destinar algunas sumas á la compra de materiales para la construcción, á fin de tenerlos almacenados, especialmente en la clase de maderas, para que estas cortadas oportunamente, y quedando secas con el tiempo, fueran más provechosas para el material que se construye y se recompone" . ${ }^{60}$

Fue a partir de 1869 que las municiones para las baterías fijas y sus cureñas se comenzaron a fabricar centralizadamente en ciudad de México, tal como la artillería comenzaría a estriarse en la Ciudadela (comenzando con calibres de 7,8 y 12)., pues "en la misma maestranza se han construido algunos montajes de hierro laminado, del todo nuevos, para las piezas de á $7 \mathrm{c}$, faltando algunos que se hallan en obra, con excepción de los montajes de á 8 y 12 para piezas rayadas, pues como es un nuevo sistema el que se emplea en esa obra, se está estudiando en la actualidad". ${ }^{61}$

\footnotetext{
${ }^{60}$ El plan de concentración de las actividades de Maestranza en la Ciudadela de la ciudad de México se basa en el argumento de que la centralización permite una administración más eficaz y facilitar su envío. Memoria que el Secretario de Estado y del Despacho de Guerra y Marina presenta al Congreso de la Unión, México, Imprenta del Gobierno, 1869, pp.77-79

61 "Las municiones para cañones que se han construido y cargado, y con las que se hallan dotadas las brigadas y baterías fijas, han sido en número de 4,525 para diferentes calibres [...] de las cuales 1,115 son para cañón rayado de á 12 c, 146 Shrappnells para el mismo calibre, 1,488 para cañón rayado de á 8 y 4000 para obús de á 16". Memoria que el, pp.79 y 81 .
} 
Ilustración 6. Fotografía de cureñas de costa móviles en Ulúa, circa 1870.

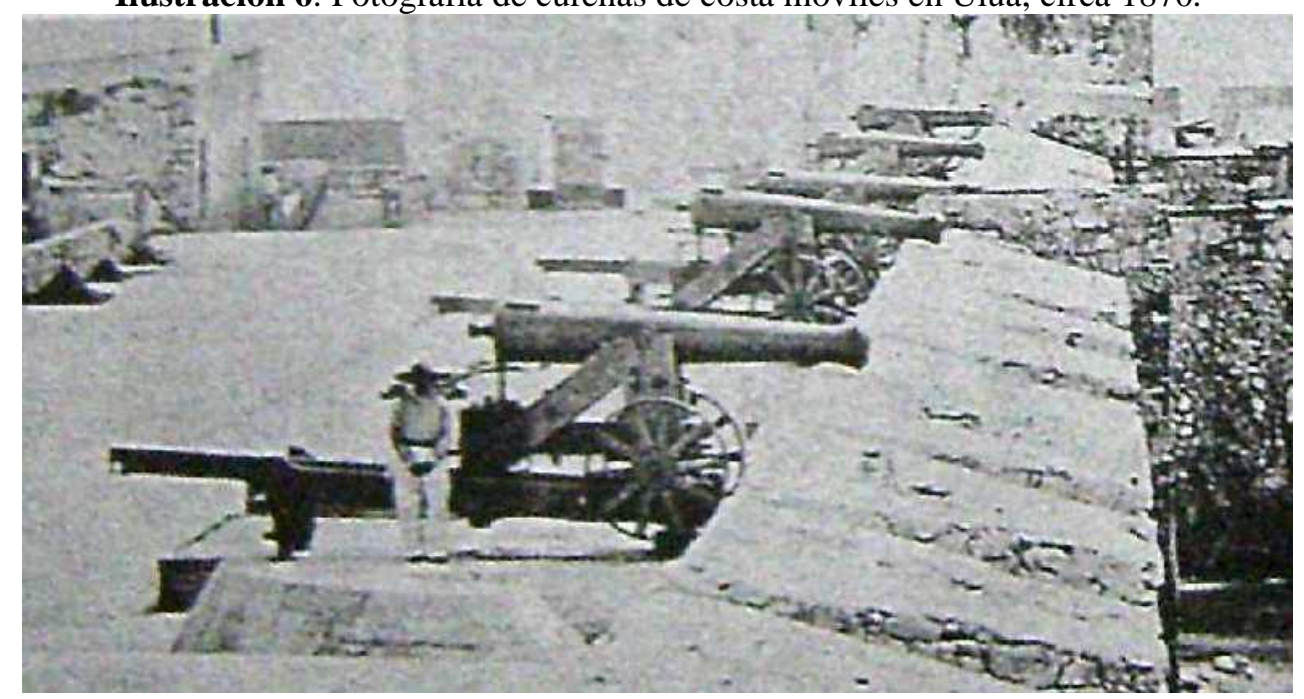

El Caballero Alto de San Juan de Ulúa observado desde el baluarte de San Pedro, es probable que fuera tomada circa 1870. Soporte en papel albuminado, "Colección Julio Michaud", Fondo: Colecciones especiales, Instituto de investigaciones Estéticas, Universidad Nacional Autónoma de México, 81 fotografías.

Por su parte, desde octubre de 1867 la artillería comenzó a producirse en la Fundición nacional de bronces adjunta a la Ciudadela, logrando fabricar en los primeros dos años 29 cañones de anima rayada " 25 son de calibre de $7 \mathrm{c}$ y 4 de á 8 c del sistema austriaco (Krupp), transformando 9 cañones de á 8 (sistema francés), que no está en uso, al de á 12c (cañón obús adoptado)". ${ }^{62}$ La artillería austriaca referida realizaba la carga por la cámara anterior, pero esto representaba un gran reto tecnológico pues se debían evitar cualquier tipo de escape de gases durante el proceso de disparo. Esto se solucionó con un mecanismo de cierre conocido como la cuña del sistema Krupp. Respecto al personal que les debía manejar, durante los primeros años de la década de 1870 se renovó la plantilla del cuerpo de artilleros en la plaza de Veracruz (por decreto del 4 de diciembre de 1871) Este cuerpo habría de denominarse "Compañía fija de artillería" de Veracruz y mantendría su sede en el Baluarte de Santiago y la fortaleza de San Juan de Ulúa. Al mismo tiempo, se comenzó sistemáticamente a reponer el material de guerra para dichas baterías. ${ }^{63}$

En la anterior ilustración del periodo se pueden apreciar las ruedas del avantrén que funcionan para su traslado luego de desempotrarlos, las hendiduras en los muros con certeza son el espacio ocupado por las ruedas del avantrén descubiertas en la más reciente intervención del Instituto Nacional de Antropología e Historia.

\footnotetext{
${ }^{62}$ Memoria que el, p.84

${ }^{63}$ Memoria que el C. Ignacio Mejía Ministro de Guerra y Marina presenta al $7^{\circ}$ Congreso Constitucional, México, Imprenta del Gobierno, 1873, p.166
} 
Ilustración 7. Fotografía de indicios arqueológicos. Autoría de Judith Hernández

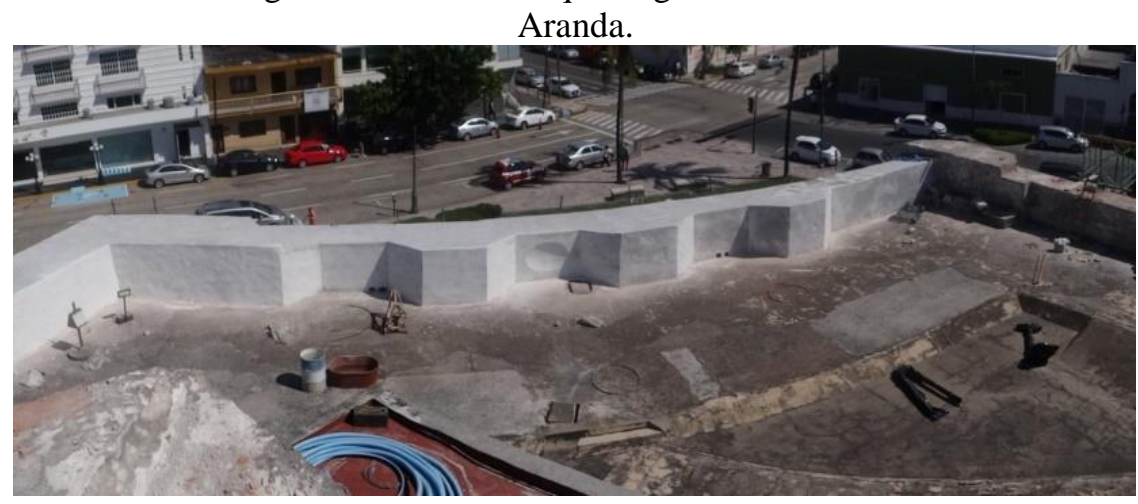

Ilustración 8. Plano del Teniente Coronal ingeniero Julio Alvarado, 1886.

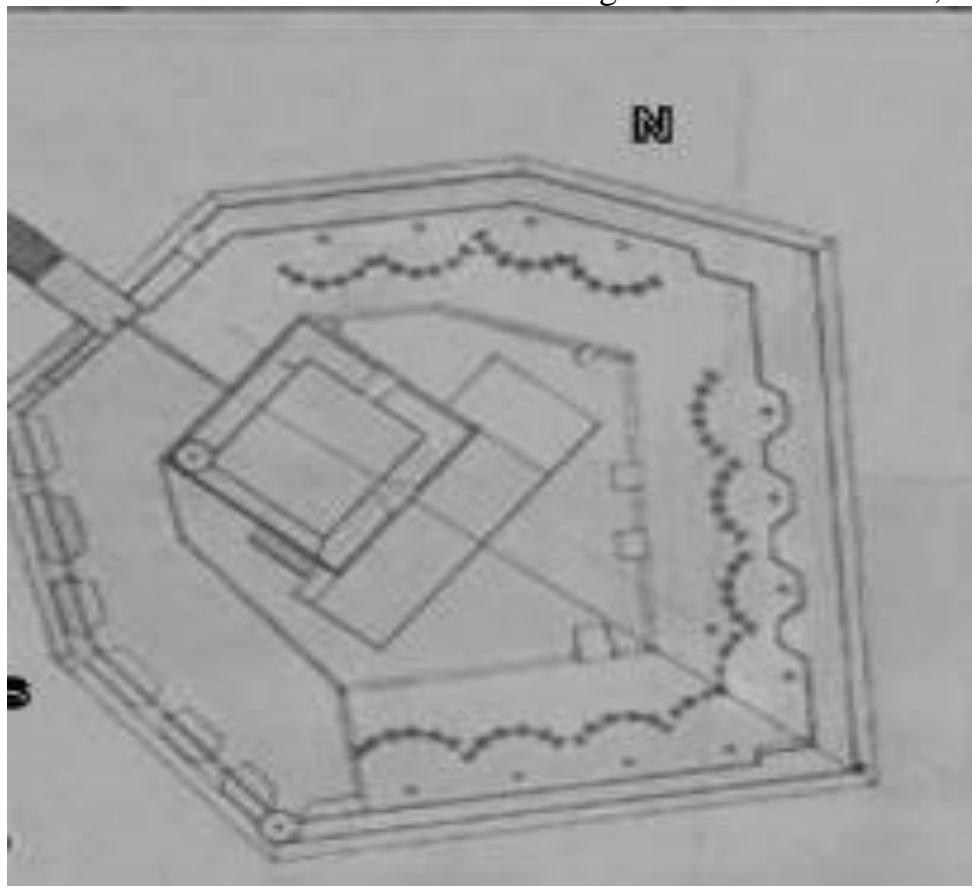

"Mapoteca Orozco y Berra", Servicio de Información Agroalimentaria y Pesquera, Secretaría de Agricultura Ganadería Desarrollo Rural Pesca y Alimentación.

Ahora bien, solo después de 1877 empezaron a construirse en la Ciudadela cureñas de hierro pero solo para la artillería de campaña. Esto indica que muy probablemente las usadas en el Baluarte de Santiago de Veracruz eran fabricadas en madera. A partir de 1881 los cañones comenzaron a fabricarse bajo una nueva técnica conocida como "Bronce-acero" siguiendo los modelos de Austria, Rusia e Italia. Consiguiendo de Estados Unidos de Norteamérica una presa hidráulica. ${ }^{64}$

En el plano anterior se observa claramente la disposición de los 12 cañones giratorios de costa. Estos con seguridad fueron fabricados en la "Fundición

\footnotetext{
${ }^{64}$ Memoria que el Secretario de Estado y del Despacho de Guerra y Marina presenta al Congreso de la Unión, México, 1 de diciembre de 1877 a diciembre de 1881, Tomo I, Imprenta del Gobierno, Tipógrafo Gonzalo a Esteva, México, 1881, pp. 27 y 31 .
} 
Nacional de artillería" de la Ciudadela y en la Maestranza Nacional pues, como señala la Memoria de Guerra y Marina de 1893, era "el único arsenal de artillería que posee el Supremo Gobierno de la Nación". ${ }^{65}$ En 1883 la Compañía fija de artillería de Veracruz estaba compuesta por: un capitán primero, un capitán segundo, dos tenientes, dos subtenientes, un guardaparque, un sargento primero, ocho sargentos segundos, dos cabos, tres clarines, un artificiero de primera, cien artilleros y dos artificieros de segunda ${ }^{66}$.

Ilustración 9. Escudo de la compañía fija de artillería de Veracruz.

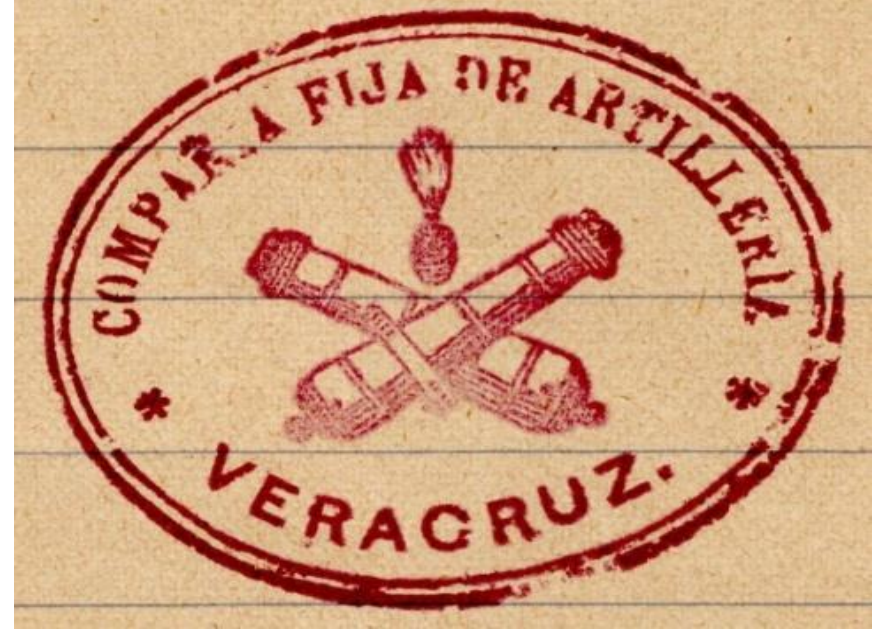

Archivo General de la Secretaría de Marina.

Las posterior Memoria de Guerra y Marina del periodo solo dan cuenta de la nueva reglamentación en la vestimenta de los artilleros y número de armas portátiles que debe portar los oficiales y la tropa de dicho cuerpo. No obstante, no detalla cambios en las piezas que manejaba la Compañía de artillería fija de Veracruz. ${ }^{67} \mathrm{El}$ armamento (proveniente de los arsenales de la Ciudadela en Ciudad de México) y cureñas anteriormente detalladas continuaron en uso durante las primeras décadas de siglo XX, pero, ¿Qué función tendrían estas añejas piezas en el nuevo siglo?

Una fuente que arroja datos sobre su último uso son las notas publicadas en la prensa de la época. La primera referencia que inauguró el empleo de la artillería del Baluarte de Santiago en la nueva centuria aparece en el diario $E l$ Correo de Sotavento de Tlacotalpan, con fecha 17 de febrero de 1901: "Al entrar al canal el crucero alemán hizo los 21 disparos de ordenanza, contestando el Baluarte de Santiago también con 21 salvas". ${ }^{68}$ Los cañones del Baluarte de Santiago en adelante fueron ocupados para dar la bienvenida

\footnotetext{
${ }^{65}$ Memoria que el Secretario de Estado y del Despacho de Guerra y Marina presenta al Congreso, Tomo I, Litografía y Tipografía de "La Época", México, 1884, p.117

${ }^{66}$ Memoria que el Secretario de Estado y del Despacho de Guerra y Marina presenta al Congreso, Tomo I, Litografía y Tipografía de "La Época", México, 1884, pp.240-241

${ }^{67}$ Véase las Memorias de Guerra y Marina de 1896 a 1899 y las subsecuentes de los años 1900, 1901 y 1903. Consultadas en el Archivo de la Secretaría de la Defensa Nacional.

${ }^{68}$ Agradezco el apoyo de la entonces encargada del acervo Silvia Sierra. Hemeroteca de El Dictamen, El Correo de Sotavento, año XXXIV, núm.3259, p.1.
} 
con 21 cañonazos a los buques extranjeros que transportaron diplomáticos, mandos militares o altos dignatarios. El siguiente evento de esta naturaleza fue registrado en una nota del diario El Dictamen de Veracruz del 10 de agosto de 1913, la llegada del diplomático norteamericano John Lind en el buque acorazado USS New Hampshire. Y ese mismo año se tiene registro del saludo con 21 cañonazos por la llegada del crucero Emperador Carlos $V$ de la Marina española, con fecha 26 de diciembre de 1913. ${ }^{69}$

En el anterior acto participó el Segundo Teniente de la compañía fija de artillería José Azueta, mismo que cuatro meses después falleció en la defensa contra la segunda intervención norteamericana. En dicho evento el Baluarte de Santiago efectuó su última acción bélica al disparar sus añejos cañones contra el USS Montana el 22 de abril de 1914 y en respuesta recibió bombardeo que lo dejó inútil, resultaba claro que ya no tendría ningún efecto útil en futuras contiendas. Así, tras el conflicto, su artillería continuó siendo usada hasta el año de 1920 tan solo para efectuar los saludos de 21 disparos, según las notas registradas en el diario El Dictamen. ${ }^{70}$

Ilustración 10. El Baluarte en 1929.

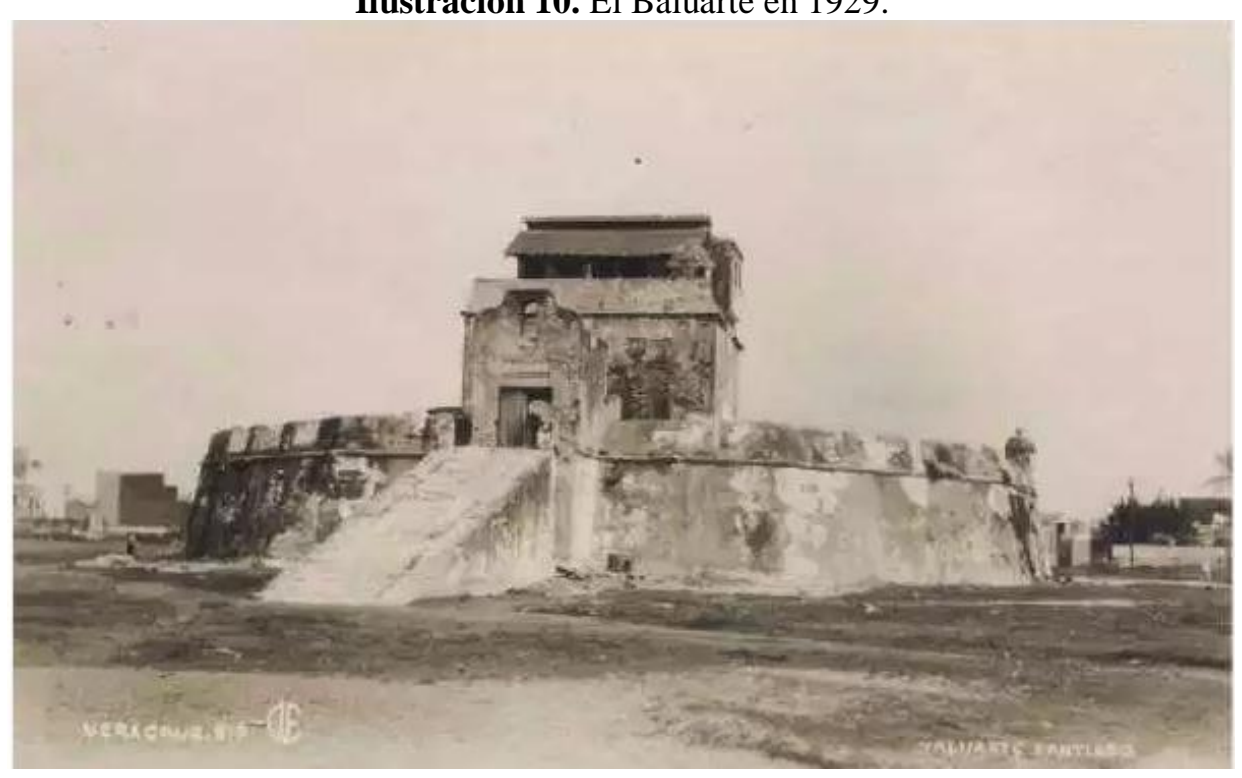

Colección Compañía Industrial Fotográfica

Esto apunta a que en una fecha posterior fueron retirados los cañones y las cureñas del baluarte pues en adelante se convirtió en oficina militar al ser sede de la Jefatura de Operaciones Militares de Veracruz en 1935, cinco años después fue entregado a la Secretaria de Marina quien le siguió dando uso administrativo, de barraca e incluso de aula provisional de la Escuela de Aviación Naval en diciembre de 1943. Para cuando, en 1954, el inmueble pasó al Ayuntamiento para ser el "Museo regional de Veracruz" es que se

\footnotetext{
${ }^{69}$ Hemeroteca de El Dictamen, El Dictamen, núm.1147, tomo XV, p.1; Hemeroteca de El Dictamen, El Dictamen, núm.1009, tomo XV, p.1.

${ }^{70}$ Me refiero a las notas con las siguientes fechas: 6 de mayo de 1917, 12 de octubre de 1917, 26 de marzo de 1919, 26 de abril de 1919, 5 de mayo de 1919, 22 de junio de 1919 y 30 de septiembre de 1920 ,
} 
rellenaron los rieles de las cureñas de madera que sostenía la artillería de costa fabricada en la Ciudadela de Ciudad de México. Con seguridad en ese mismo periodo fueron colocados los cañones con fines de ornato y sus históricamente erróneas bases de fierro, puesto que existen evidencias fotográficas de mediados del siglo XX que muestran ya los cañones en su disposición actual.

\section{Consideraciones finales}

Luego del bombardeo a San Juan Ulúa de fines de 1838, el gobierno mexicano deseó emprender reformas encaminadas a la modernización de la artillería de los dos principales baluartes de Veracruz (Concepción y Santiago). No obstante, haberse ordenado un primer proyecto de contrata basado en tecnología inglesa en 1842, las fuentes señalan una crónica incapacidad de contar con sistemas de cureñaje acordes a su tiempo y a las necesidades.

La guerra de intervención norteamericana (1846-1848) impidió la cristalización total de los esfuerzos. Se colocaron "cañones bomberos" y morteros en gradual sustitución de los cañones, pero se careció de cureñas adecuadas y hasta 1852 el estado en general seguía siendo ruinoso. La inestabilidad del Estado mexicano decimonónico impactó en el ámbito de la tecnología militar disponible en el Baluarte de Santiago; los gobiernos liberales abogaban por la producción nacional de cureñas mientras que los conservadores realizaban contratos para adquirirlas en el extranjero a través de particulares (como sucedió en 1854). Este cambio de planes retardo cualquier proyecto modernizador de los baluartes y los conflictos intestinos hicieron trasladar mucha de la artillería de la plaza de Veracruz a otros sitios, disminuyendo dramáticamente hacia 1857. Además, la Guerra de reforma (1858-1861) y la Segunda intervención francesa (1862-1867) siguieron aplazando la urgente mejora en los instrumentales bélicos, para entonces el atraso era de décadas en comparación con la artillería de costa en Europa y Norteamérica. Habría que señalar el periodo posterior a 1870 como el de la colocación de las cureñas de marco en eje giratorio (tal y como apunta la evidencia fotográfica del Baluarte de la Concepción y San Juan de Ulúa circa 1873)

Los marcos estaban basados en modelos españoles e ingleses de la década de los 40’s. Con seguridad (a pesar de la preferencia de los tratados europeos por usar hierro) estos y todo el cureñaje fue fabricado de madera en la Maestranza de La Ciudadela y los cañones eran de bronce producto de la contigua Fundición Nacional en Ciudad de México. El calibre de estas piezas era de 24 libras (siguiendo el antiguo sistema francés por el peso de la bala) aunque, debido a que comenzaban a ser de ánima rayada, empezaron calibrarse por el sistema de medición de longitud del rayado (6.4 pulgadas o 16 centímetros). Manteniendo aún el vetusto sistema de retrocarga en lugar de la moderna avancarga, empero esto fue cambiando gracias a la habilidad de los artesanos e ingenieros militares mexicanos que aplicaron el sistema de cuña de Krupp. 
El diseño de las cureñas y sus rieles, documentados por el Teniente coronel Julio Alvarado en 1886, no fueron una calca exacta de ningún tratado europeo (alemán o ingles) de la época, no pueden en encasillarse en tipologías como el modelo Moncrieff. Fue la mezcla del montaje de marco alto para barbeta del modelo anglosajón y español, de tres décadas atrás, con la inventiva nacional que les añadió un avantrén (que rozaba el muro) para rápidamente desempotrar la pieza y movilizarla de ser necesario. Por tanto estamos ante un sistema de cureñaje mestizo, que no siguió la preferencia occidental por fabricarse en hierro sino que usó maderas locales, decisión que debió estar influida por economía y medio ambiente de Veracruz. Por todo lo expuesto, es prioritario el rescate del patrimonio militar del Baluarte de Santiago con la exactitud histórica que se merece un recinto que ha participado en las principales gestas defensivas de la soberanía país. Con el respeto que merece el armamento de grueso calibre y las cureñas que les sostenían, como objetos culturales.

No obstante, la actual museografía no representa adecuadamente el largo proceso histórico que significó la adquisición de armamento en los diferentes cambios políticos y sociales de México, por lo que se solicita enfáticamente poner mantener los indicios de los rieles de las cureñas y del avantrén en los muros. Esto como parte integral en un futuro proyecto que tenga por objetivo recrear los tipos de piezas señalados en este estudio, mismos que son ejemplos de la historia de la industrialización y de la inventiva nacional. Es necesario un nuevo enfoque que proyecte al Baluarte como un recinto único en México dedicado al Patrimonio histórico militar (entendido como inmueble y muebles relacionados con la cultura de la Defensa). Basado en el tercer considerando del decreto del 26 de junio de 1954 sobre creación del Museo de Historia Regional (publicado en el Diario Oficial de la Federación) que señala la necesidad de conmemorar "los hechos de armas en lo que, de forma preeminente, participó el pueblo veracruzano en defensa de la Patria”.

\section{Bibliografía}

\section{Fuentes primarias:}

Archivo General de Indias (AGI), Audiencia de México, 28.

AGI, Mapas, planos y dibujos, (años 1503-1805). vol. I.

AGI, Mapas, planos y dibujos, Ingenios, 30.

Archivo del Museo Naval de Madrid (AMN), Juan José Navarro, Diccionario demostrativo con la configuración y anatomía de toda la arquitectura naval moderna, Madrid, 1756.

Archivo General de la Nación (AGN), Historia, vol. 362.

AGN, Gobierno Virreinal, Marina, 068, vol. 27. 
AGN, Indiferente Virreinal, Caja 1-999/Caja 0618, 1771, Expediente 012.

AGN, Indiferente de Guerra, vol. 276.

Hemeroteca digital de El Dictamen (HDD), El Correo de Sotavento, año XXXIV, núm.3259, p.1.

HDD, El Dictamen, núm.1147, tomo XV, p.1.

HDD, El Dictamen, núm.1009, tomo XV, p.1.

Biblioteca de la Secretara de la Defensa Nacional (BDN), S/a. "Comprehende las Ordenanzas que corresponden al real cuerpo de artillería e ingenieros. Árbitros aplicados a las obras de fortificación y academias de matemáticas para la tropa", t. VI, en Colección General de Ordenanzas militares, sus innovaciones y aditamento, dispuesta en diez tomos, desde 1553 hasta 1758, Madrid, impresa por Antonio Marín por orden de José Antonio Portugués, 1765.

Ciscar, José, Cartilla de artillería de Marina para el uso de los guardias marina, Madrid, Imprenta Real, 1830.

Esclus, José María Curso completo del arte y de la historia militar. Epitome de cuanto se ha escrito hasta el día sobre el arte de la guerra, Imprenta del Siglo a cargo de Ivo Biosca, Madrid, 1845.

Lerdo de Tejada, Miguel, Apuntes Históricos de la Heroica ciudad de Veracruz, Tomo II, México, Imprenta de Vicente García Torres, 1857.

Memoria del Ministro de Guerra y Marina, presentada a las cámaras del Congreso General Mexicano, en Enero de 1840, México, Oficina el Águila, 1840.

Memoria del Secretario de Estado y del Despacho de Guerra y Marina, leída a la cámara del Congreso Nacional, México, Impresa por Ignacio Cumplido, 1844.

Memoria del Secretario de Estado y del Despacho de Guerra y Marina, leída a la cámara del Congreso Nacional, Impresa por Ignacio Cumplido, México, 1845.

Memoria del Secretario de Estado y del Despacho de Guerra y Marina, leída a la cámara del Congreso Nacional, Impresa por Ignacio Cumplido, México, 1846.

Memoria del Secretario de Estado y del Despacho de Guerra y Marina, leída a la cámara del Congreso Nacional, Imprenta de Vicente García Torres, México, 1849.

Memoria del Secretario de Estado y del Despacho de Guerra y Marina, leída a la cámara del Congreso Nacional, Imprenta de la calle de Medina México, 1850.

Memoria del Secretario de Estado y del Despacho de Guerra y Marina, leída a la cámara del Congreso Nacional, México, Imprenta de Vicente García Torres, 1852. 
Memoria del Ministerio de Guerra y Marina, presentada al primer Congreso Constitucional de 1857, Imprenta de Juan B. Navarro, 1857.

Memoria que el Secretario de Estado y del Despacho de Guerra y Marina presenta al Congreso de la Unión, México, Imprenta del Gobierno, 1869.

Memoria que el C. Ignacio Mejía Ministro de Guerra y Marina presenta al $7^{\circ}$ Congreso Constitucional, México, Imprenta del Gobierno, 1873.

Memoria que el Secretario de Estado y del Despacho de Guerra y Marina presenta al Congreso de la Unión, México, 1 de diciembre de 1877 a diciembre de 1881, Tomo I, Imprenta del Gobierno, Tipógrafo Gonzalo a Esteva, México, 1881.

Memoria que el Secretario de Estado y del Despacho de Guerra y Marina presenta al Congreso, Tomo I, Litografía y Tipografía de "La Época", México, 1884.

Morla, Tomás de, Laminas pertenecientes al tratado de artillería que se enseña en el Real Colegio Militar de Segovia, edición facsimilar, vol. II, Segovia, Patronato del Alcázar de Segovia, 1993.

Paso y Troncoso, Francisco del, Diario de las operaciones militares del sitio de Puebla de 1863, Gobierno del Estado de Puebla, Secretaría de Cultura, Puebla, 1988.

Villaseñor y Sánchez, Joseph, Theatro Americano. Descripción General de los Reynos, y provincias de la Nueva España, y sus jurisdicciones, Impresora del Real y Apostólico Tribunal de la Santa Cruzada en todo este Reyno, México, 1746.

\section{Fuentes secundarias}

Bravo Ugarte, José, “El conflicto con Francia de 1829-1839”, En Historia Mexicana, Núm. 4, 1953, pp. 477-502.

De Crouy-Chanel, Emmanuel, "Charroi de l'artillerie et construction de l'État moderne en France dans le dernier quart du XVe siècle" en Aude Mairey et al, "Contre-champs". Études offertes à Jean-Philippe Genet, Paris, Classiques Garnier, 2016, pp. 159-176.

Gallegos, Eder, "La artillería novohispana ante el fantasma de invasión naval, 17621808”, En Revista Tiempo y Espacio, Núm. 64, 2014, pp.192-216.

Gaspar Covarrubias, Mario, "El baluarte de Santiago y los 500 años de fundación de la actual ciudad de Veracruz", https://efacico.wordpress.com/2017/10/10/elbaluarte-de-santiago-y-los-500-anos-de-fundacion-de-la-actual-ciudad-deveracruz/ (Consulta: 24/03/2018)

Guía, Germán, "La artillería costera rayada en Venezuela: Innovación tecnológica en la Regeneración Guzmancista (1875-1876)", en Revista Tiempo y Espacio, Núm.67, 2017, pp. 63-111. 
Leonard, Irving, "Informe de Don Carlos de Sigüenza y Góngora sobre el castillo de San Juan de Ulúa (1695)", En Revista de Historia de América, Núm. 45, 1958, pp. 130-143.

Richardson, Alex, Vickers, Sons and Maxim, Limited: Their Works and Manufactures, Londres, Offices of "Engineering", 1902.

S/a, Catálogo del Museo Nacional de Artillería, Talleres del Departamento de Estado Mayor, México, 1910.

S/a, Los primeros consulados de México 1823-1872, México, Secretaría de Relaciones Exteriores, 1974.

S/a, ¡No solo cañones!: Exposición temporal-Museo del Ejército. Madrid, Centro Geográfico del Ejército, 2014. 